\title{
A Critical Appraisal of Human Resource Planning, Recruitment and Selection Processes at Hotel Kong Frederik
}

\author{
Wen BAI, Yajun ZHAO \\ Department of Economics, Shenyang TV\& Broadcast University \\ Department of Foreign Language, Shenyang TV\& Broadcast University
}

\begin{abstract}
Hotel Kong Frederik is a four-star luxury hotel situated by the Town Hall Square in central Copenhagen. This paper introduced how the hotel manager made human resource planning and how recruited and selected staff. Then the paper evaluates whether the human resource planning and the methods of training and staff development at Hotel Kong Frederik are reasonable and valuable. To write this paper, the author has interviewed the hotel manager and collected the primary information directly from the Hotel manager, Ms Hanne Hassen. The hotel manager mainly operated the reception, IT and technology departments, which is why this paper is concerned with these departments.
\end{abstract}

Index Terms - human resource recruitment and selection processes training and staff development

\section{Introduction}

Hotel Kong Frederik is a four-star luxury hotel situated by the Town Hall Square in central Copenhagen. In the vicinity of Hotel Kong Frederik, it is surrounded by the Copenhagen Town Hall, the main pedestrian street, Strøget, Tivoli Gardens and the Central Station. This central address qualifies Hotel Kong Frederik as one of the best-located hotels in Copenhagen [4].

However, to the customers, the perfect location and marvellous facility design are the appearance of the hotels' managing service operation. To the hotels' operational strategies, there is no doubt that human resource planning, recruitment and selection process, training and staff development play essential roles.

The purpose of this paper is going to introduce how the hotel manager made human resource planning and how recruited and selected staff. Then the paper evaluates whether the human resource planning and the methods of training and staff development at Hotel Kong Frederik are reasonable and valuable.

\section{Human resource planning $(H R P)$}

Gold (2003) states that 'Human resource planning is the process of systematically forecasting the future demand and supply for employees and the deployment of their skills within the strategic objectives of the organisation.[1]' Moreover, human resource planning has strategic and operational characteristics.

\section{Strategic HRP between the Remmen hotels and Hotel Kong Frederik :}

Strategic HRP 'links to strategic implementation and action, to change management and links to financial planning and budget formulation [5]'. As one of the members of the Remmen hotels, Hotel Kong Frederik shares accounting, sales and reservation departments with the other hotels and cooperates with ISS since all the housekeeping departments belong to this largest cleanness company in Denmark. The Remmen hotels' management holds the right to change each hotel manager and the financial statement of each hotel needs to be reported to the Remmen hotels annually. If the applicants apply for a position at one of the Remmen hotels that doesn't have any vacancy, the applicants can be introduced to the other hotels. During the busiest season the employees even can be lent to the other hotels. Therefore between the Remmen hotels and Hotel Kong Frederik, the human resource planning can be considered as a strategic HRP model.

\section{Operational HRP at Hotel Kong Frederik:}

Operational HRP is 'the comparison of an organisation's existing labour resources with forecasting demand and hence the scheduling of activities for acquiring, training, redeploying and discarding labour [6]'.

However, as a medium hotel in Copenhagen, Hotel Kong Frederik needs to implement and operate a specific human resource planning by itself. The hotel manager does manpower planning, recruitment and selection process and divides this hotel into several departments that are reception, IT, technology, housekeeping, restaurant and kitchen. According to the previous annual financial statements of the hotel, the manager makes decision on the human resource planning yearly. She forecasts how many employees will be required in the forthcoming year and determines whether the hotel needs to supplement new employees or discard some employees. She also makes plan on how to train staff and how to select the staff. 


\section{The advantages and disadvantages of the HRP at Hotel Kong Frederik:}

HOLBECHE (2000) claims that strategic HRP is closer to the alignment and better to the organisational responsiveness, and hence the ability of strategic HRP will adapt to the customer needs and maintain competitive advantage [7].

This also reflects the strategy of the Remmen hotels. Sharing the accounting, sales and reservation departments with other hotels, Hotel Kong Frederik will spend less variable cost on the wages of employees. To introduce the applicants to the other hotels, each hotel will spend less time and expense on looking for new employees. Some employees can be lent during the busiest season, which can effectively utilise the human resource among the Remmen hotels.

Even though Hotel Kong Frederik has got a lot of benefits from the Remmen Hotels and the hotel manager has an own power to make operational HRP implement the human resource management. Meanwhile, it has more duties than a single hotel because it has made HRP based on financial situation of the Remmen Hotels. This means that the Remmen hotels own more power than each hotel, which could restrict the flexibility of Hotel Kong Frederik.

\section{Recruitment and Selection process:}

If HRP is a planning process and can be considered as an initiatory operation, recruitment and selection will be an implementation procedure. Boella (1992) argues that recruitment and selection is the process to attract suitable applicants among a pool of capable people who may be selected for a particular job [2].

Riley (1991) discusses that the recruitment process contains four elements: the hiring standard (what you want); the target market (where you think you will find it); the sources of recruitment (by what means you intend to get it); and the cost (how much you are prepared to invest in the search) [3].

\subsection{The hiring standard:}

11 full time and 8 part time receptionists consist of the reception of Hotel Kong Ferderik. Each full time receptionist studied hotel manager or receptionist course and graduated from secondary colleges. The part time receptionists are all students from the universities. In fact the hotel manager said that she did not care the employees' educational level too much but preferred the applicants who have work experience or some experiences of serving the customers. On the other hand, the ages of the employees are also important because young people like some teenagers are too young to be responsible with their duties. Therefore the average age of the receptionists is around 25 years old at this hotel. The hotel manager also mentioned that the applicants' hobbies and interests are a significant factor to choose the suitable person. The reason is that the person who has some positive and active hobbies and interests is more acceptable and pleased to the customers.
Moreover, due to the work time and social unrest, most receptionists are male to work during the midnight and earlier morning every day. Among the receptionists, five female and fourteen male have shown the gender unbalance. At IT and technology department there are two employees working. They must have professional skills and work experiences. Such as at Hotel Kong Frederik there is a special hotel computer system called 'FIDELIO', so the employees must be skilled and be familiar with the system before they start working.

\subsection{The target market:}

At Hotel Kong Frederik, the manager rarely makes announcement search for the staff. Due to co-operate with the other sister hotels, the applicants could be changed among the Remmen Hotels. In addition, some people who are friends of the current employees and want to work at the hotel will be introduced to the manager. Moreover, university students prefer doing part time works and full time work in summer. Full time employees are all from the secondary colleges, therefore the university students and graduates from the secondary colleges can be the target candidates.

\subsection{The sources of recruitment:}

There are several sources to look for suitable candidates. However, thought of the cost and number of employees, the hotel ranks the sources of recruitment at three levels.

Firstly, the hotel manager normally prefers the applicant who is introduced by the existing employees. This method could be more creditable and faster. And the cost is almost nothing. Secondly, due to the cost of advertising, the Internet is more and more popular method to look for the applicants and do not spend too much cost. So Hotel Kong Frederik also puts the advertising on the homepage of the Remmen Hotels when they need to supplement the employees. Furthermore, it is a viable way to resort some job agencies and local newspapers or to contact universities and colleges.

\subsection{The cost:}

The hotel manager said it depended on what employees they need. Normally they will not pay too much on the recruitment of receptionist. But for the IT and technology department, the hotel requires the employees with the professional skills. Those employees are recommended by the job agencies and job centers so that there is the guarantees between the hotel and employees. It is more expensive to get a suitable and right person than receptionists.

\subsection{Selection:}

Hackett (1991) states that selection is concerned more with "predicting which candidates will make the most appropriate contribution to the organization- now and in the future [8]".

- What kinds of the candidates does the hotel need?

As the hotel manager said, 'I do look for staff with a lot of experience, not too young. They need to be stable and flexible, as working hours can be quite hectic.' Be active and 
mature, it can be the most important factor to choose the candidates for the Hotel Kong Frederik. On the other hand, work experience and former service experience are also essential elements that the candidates must have.

- How did the manager select the candidates?

The hotel manager often gets the applications that sent to the Hotel or to the other sister hotels. Everybody get answers, but some are positive, some are negative. This means the hotel manager will pick out some applications that show that the applicants are more suitable with the job position than the others, and then these applicants will get positive answer to meet the manager. Opposite to this, it means the applicants have failed the application because of their insufficient and unsatisfied background and personal statements. During the interview, the manager will investigate the applicants' work experience, behavior and personality. As one of the parts of recruitment and selection process, the second function of interview is to attract the applicants to the job and to display the essential expectations and requirements of the job. Thus, the manager will introduce how the job is liked to the candidates during the interview as well as the applicants have to introduce themselves.

However, these processes do not show any differences, new technologies and competitive advantages that are more than the other hotels.

4.6The advantages and disadvantages of recruitment and selection process at Hotel Kong Frederik

Recruitment and selection process is not only an operational procedure but also a competitive strategy. In central Copenhagen, there are 32,098 university students [9]. Accepting some university students as part time employees, the manager diminishes the shortages on the supplement of succession. The reason is that the busiest season at the hotel is in summer and Christmas and normally these periods are university students' holidays. Therefore at that time part time employees can supplement the succession. By using of several sources of recruitment, low hiring standard and less cost of the recruitment can be more convenient and effective on the recruitment process.

However, at Hotel Kong Frederik, the recruitment and selection process utilises traditional methods. With the development of economy and technology, foreign residents, about $7 \%$ total population of Copenhagen, come to the city and look forward to finding a job as well as the local residents. At the external circumstance, it is necessary to consider laws and regulations, national culture, unions, and labour markets on the recruitment and selection process, whereas at the internal circumstance, the lacks of technology and competitive strategy and gender unbalance of the employees still need to be improved on recruitment and selection process.

\section{Conclusion:}

This paper mainly sets out three parts that are HRP, recruitment and selection process, training and staff development. It displayed how is operated HRP, recruitment and selection process at the Hotel Kong Frederik. Between the Remmen Hotels and Hotel KongFrederik, the strategic HRP reduces the variable cost of the employees' wages and spends less time and cost on the recruitment process because of sharing the account, sales and reservation departments.

At Hotel Kong Frederik, the recruitment process uses several sources of recruitment, low hiring standard and spends less cost of the recruitment. Accepting the universities students enlarge the range of the candidates and supplement the succession. However, as a proverb says 'a coin always has two sides'. There are still blemishes on the human resource management at Hotel Kong Frederik. As a member of the Remmen Hotels, Hotel Kong Frederik's profit and loss should be related to the Remmen Hotels and the hotel's own HRP has been based on the Remmen Hotels' financial situation. This might restrict the development of Hotel Kong Frederik.

In such a brief study, it is hardly to say what exactly will be useful to enhance the human resource management at Hotel Kong Frederik in the future. However, it will be helpful to improve the quality of service if the employees get some training lectures to enrich their knowledge and skills. With the development of economy and technology, the degree of rival is more and more intense. Therefore it is significant to make progress on the disadvantages of the human resource management at the inside of the hotel.

\section{References:}

[1] Bratton,J and Gold,J (2003, $3^{\text {rd }}$ edition) Human Resource Managementtheory and practice published by palgrave Macmillan

[2] Boella, M.J $\left(1992,5^{\text {th }}\right.$ Ed) Human Resource Management In The Hospitality Industry published by Stanley Thrones Ltd

[3] Riley, M.J (1991) Human Resource Management-A guide to personnel practice in the hotel and catering industries published by ButterworthHeinemann Ltd, Linare House, Jordan Hill, Oxford OX2 8DP

[4] Source: http://www.remmen.dk/kongfrederik/index.htm

[5] Source: learning materials at university of Brighton

[6] Source: learning materials at university of Brighton

[7] Source: learning materials at university of Brighton

[8] source: Beardwell, I and Holden, L (2001) Human Resource Management-A contemporary approach

[9] source: http://www.earcmn.org/html/eng/education/denmark.html 